\title{
Synovial Sarcoma of the Spine: A Rare Intradural Extramedullary Tumour
}

\author{
Ajay Sebastian Carvalho $M C h^{1}$, Kishan Kumar Yadav $M C h^{2}$, Vijay Kumar Gupta $\mathbf{M C h}^{3}$ \\ ${ }^{1}$ Department of Neurosurgery, Command Hospital (Southern Command), Pune, India, ${ }^{2}$ Department of Neurosurgery, \\ Command Hospital (Eastern Command), Kolkata, India, ${ }^{3}$ Department of Neurosurgery, National Institute of Medical \\ Sciences and Research, Jaipur, India
}

Date of submission: $4^{\text {th }}$ July 2020

Date of acceptance: $30^{\text {th }}$ September 2020

Date of publication: $1^{\text {st }}$ December 2020

\section{Abstract}

Synovial sarcoma (SS) accounts for 5- 10\% of all adult soft-tissue sarcomas and only $5 \%$ arises in the spine. It presents like any other spinal tumor, namely axial pain with symptoms due to neural compression. Imaging findings can also be similar to any other benign spinal tumor.

We present a 43-year-old male who presented with symptoms of radiculopathy and neural compression and imaging revealed a dumbbell tumor at C6 to D1 with transforaminal and paraspinal extension on the right side. After surgical excision the histopathology revealed a rare synovial sarcoma of the spine.

Synovial sarcoma of the spine though rare, are difficult to differentiate based on their presentation and imaging characteristics from benign spinal tumors. However, subtle findings on imaging and a pre-operative biopsy may aid in performing a more definitive surgery upfront rather than a re-do surgery after the histopathological diagnosis.

Key words: Intradural extramedullary, Marginal margins, Synovial sarcoma, Triple signal intensity

Abbreviations: SS - Synovial Sarcoma, MRC - Medical research Council

\section{Introduction}

ynovial sarcoma (SS) is a rare condition confirmed by $\checkmark$ the fact that it accounts for only $5-10 \%{ }^{1}$ of all adult soft-tissue sarcomas and only $5 \%$ arises in the spine. It is

Access this article online
Website: https://www.nepjol.info/index.php/NJN
DOI: https://doi.org/10.3126/njn.v17i3.33125
HOW TO CITE
Carvalho AS, Yadav KK, Gupta VK. Synovial Sarcoma of the
Spine: A Rare Intradural Extramedulary Tumour. NJNS.
2020;17(3):45-49

${ }^{1}$ ORCID id: 0000-0001-9558-7008

${ }^{2}$ ORCID id: 0000-0001-7817-1780

${ }^{3}$ ORCID id: 0000-0002-3959-3363

Address for correspondence:

Colonel (Dr) Ajay Sebastian Carvalho

Department of Neurosurgery,

Command Hospital Southern Command, Pune 411040

E-mail: ajayneuro0404@gmail.com

Tel: +91-7754935318

Phone: +91- 9343953457

Copyright (C) 2020 Nepalese Society of Neurosurgeons (NESON)

ISSN: 1813-1948 (Print), 1813-1956 (Online)

This work is licensed under a Creative Commons Attribution-Non Commercial 4.0 International License. more of a histopathological diagnosis rather than a clinical diagnosis. Its clinical presentation is similar to any other spinal tumor. However, subtle findings on MRI and a needle biopsy before the surgery will aid in performing a definitive surgery upfront. This case report aims to sensitize the surgical community of the above facts.

\section{Clinical History}

A forty-three years male presented with weakness, tingling and numbness of right hand and forearm for 6 months which started after trying to shift a heavy object from the second floor to the ground floor. He complained of pain radiating to both upper limbs with decrease in sensation over the right upper limb. He had gait imbalance $\&$ started experiencing frequent falls.

General systemic examination was grossly normal. Neurological examination revealed wasting of right arm, forearm, hand muscles, with increased tone in lower limbs and power of MRC grade 4/5 in proximal and 3/5 in distal muscles of his right upper limb. Power in his lower limbs was MRC 4/5 all groups. His right-hand grip was $20 \%$, deep tendon jerk revealed absent right triceps jerk and brisk left upper limb and both lower limb reflexes with equivocal bilateral plantars. He had decreased pain, touch and temperature sensation over the right upper limb, joint position \& vibration sensation were lost in bilateral lower 


\section{Carvalho et al}

limbs. Rhomberg's sign was positive. Examination of his spine did not reveal any tenderness or abnormal mobility.

$\mathrm{X}$-ray of the cervical spine revealed no evidence of any vertebral lesions (Figure 1).

Contrast Enhanced MRI of the cervical spine showed an intraspinal lesion extending from C6 to D1 with homogeneous contrast enhancement causing cord compression with extension through into the paraspinal muscles (Figure 2a, 2b).

Patient underwent laminectomy of C6, C7 and D1. A large intradural component was seen with intra-tumoral bleed, which was excised in-toto (Figure 3a). The lesion was seen exiting out of the intervertebral foramen into the paraspinal region (Figure $3 b$ ). Near total excision of this part was achieved. The tumour was vascular, pinkish, soft and suckable.

Histopathology was suggestive of high-grade malignant tumor showing both epithelial and mesenchymal differentiation suggestive of synovial sarcoma (Figure 4).

The histopathology revealed tumor tissue with variegated appearance composed of round to oval and spindle cells. The round-to-oval cells were arranged in patternless sheets, showing perivascular arrangement. The round cells had scant eosinophilic cytoplasm, high $\mathrm{N}: \mathrm{C}$ ratio, pleomorphic hyperchromatic nucleus with inconspicuous nucleoli. These cells showed an admixture with cells displaying vesicular nucleus and prominent nucleoli. The spindle cells were arranged in fascicles and whorls, they had eosinophilic cytoplasmic processes, central elongated nucleus with coarse chromatin pattern. Large areas of necrosis and brisk mitosis were seen. Immunohistochemistry (IHC) showed CK, EMA were Positive in the round cells, Vimentin positive in both

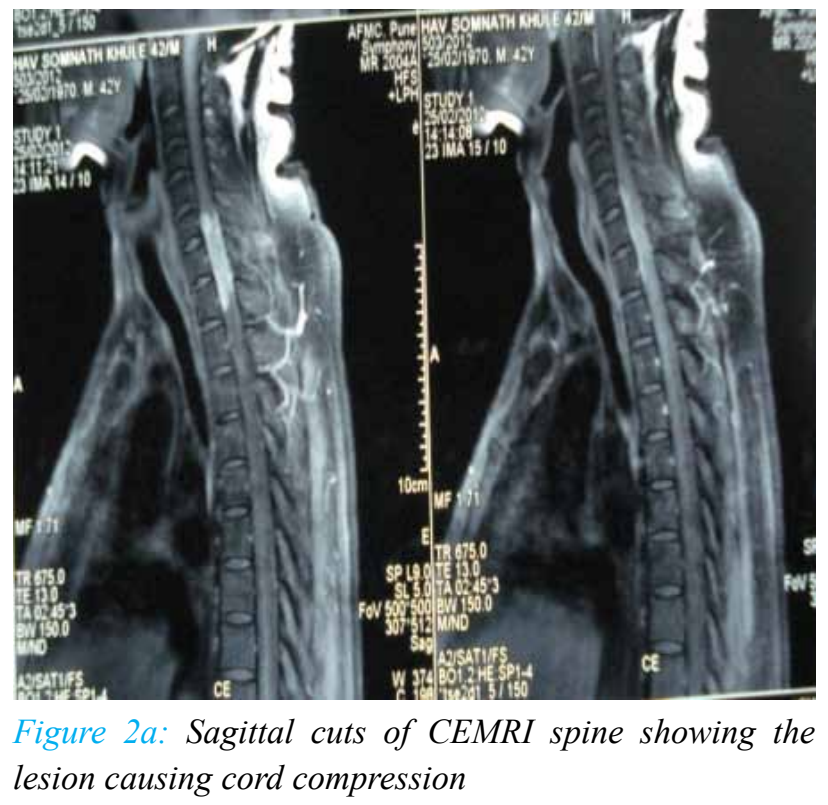

spindle and round cells and LCA, HMB-45, CD99, CD34, GFAP, CD 10 and Calretinin were negative in both round \& spindle cells (Figure 4). IHC interpreted the tumor as a high-grade malignant tumor showing both epithelial and mesenchymal differentiation suggestive of synovial sarcoma.

During the post-operative period, the power in his right upper limb improved to MRC $4 / 5$ in all groups. He was ambulant, continent and the wound healed well. The case was then referred to the radiation oncologist for further management, the patient survived for 24 months after which he developed metastasis and succumbed.

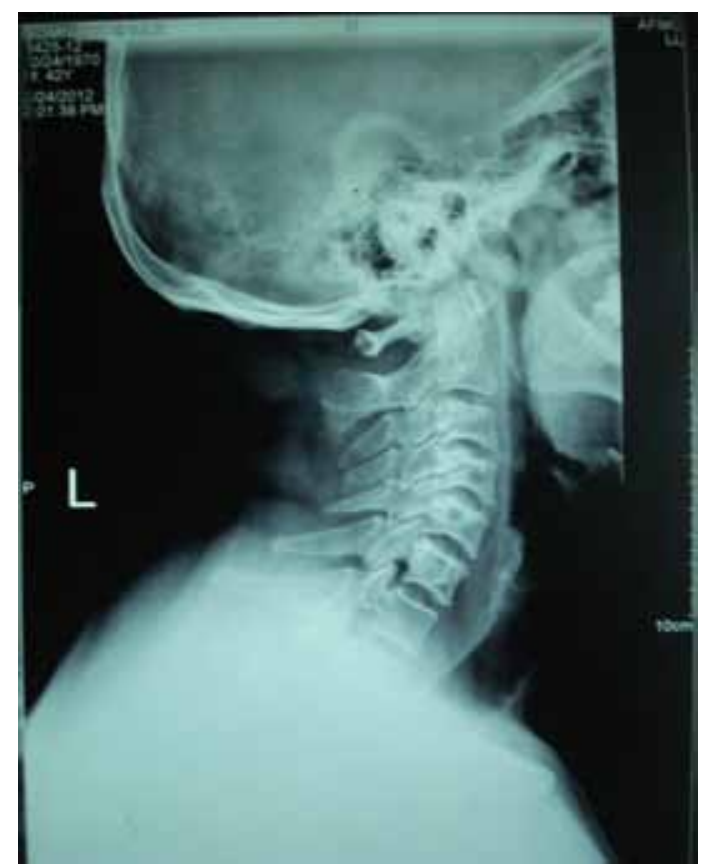

Figure 1: X-ray of the cervical spine

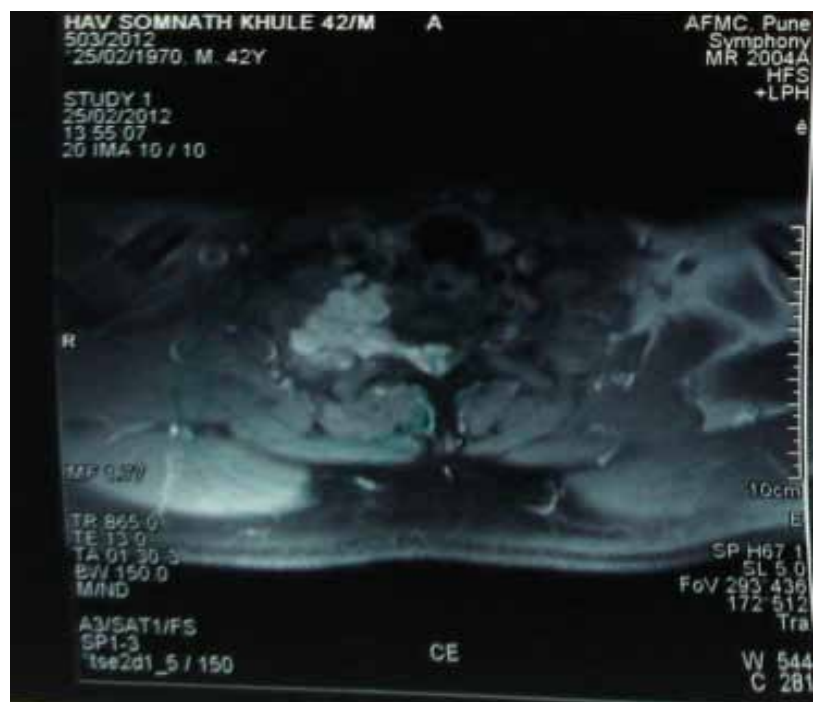

Figure 2b: Axial cuts of CEMRI spine showing the lesion causing cord compression and paraspinal extension 


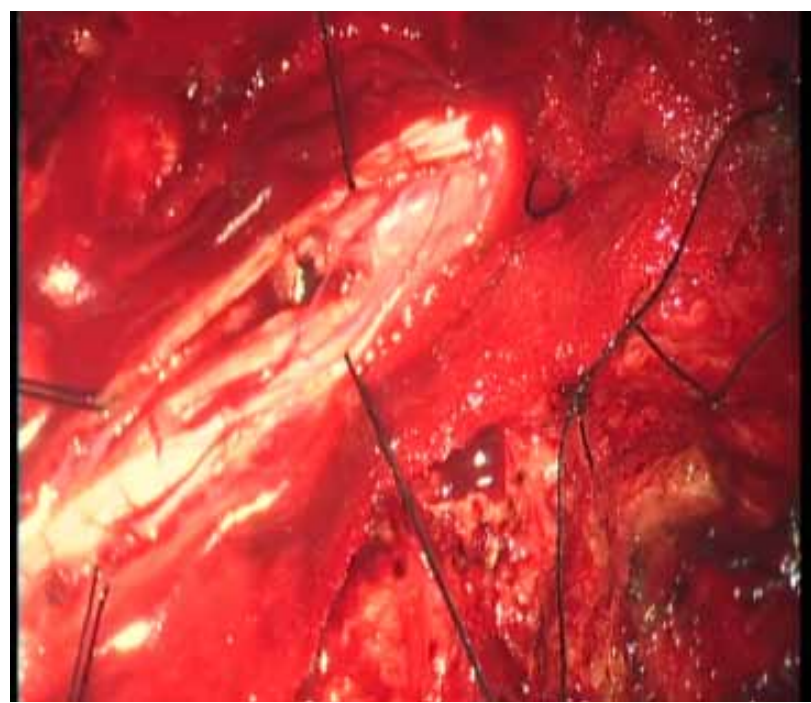

Figure 3a: Intradural part with bleed being removed

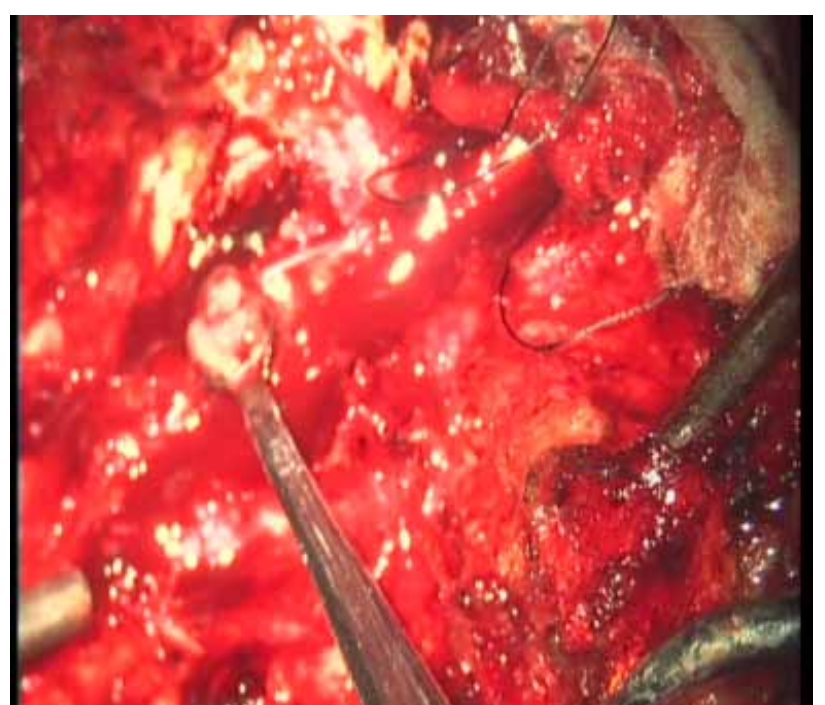

Figure 3b: Extradural part being removed
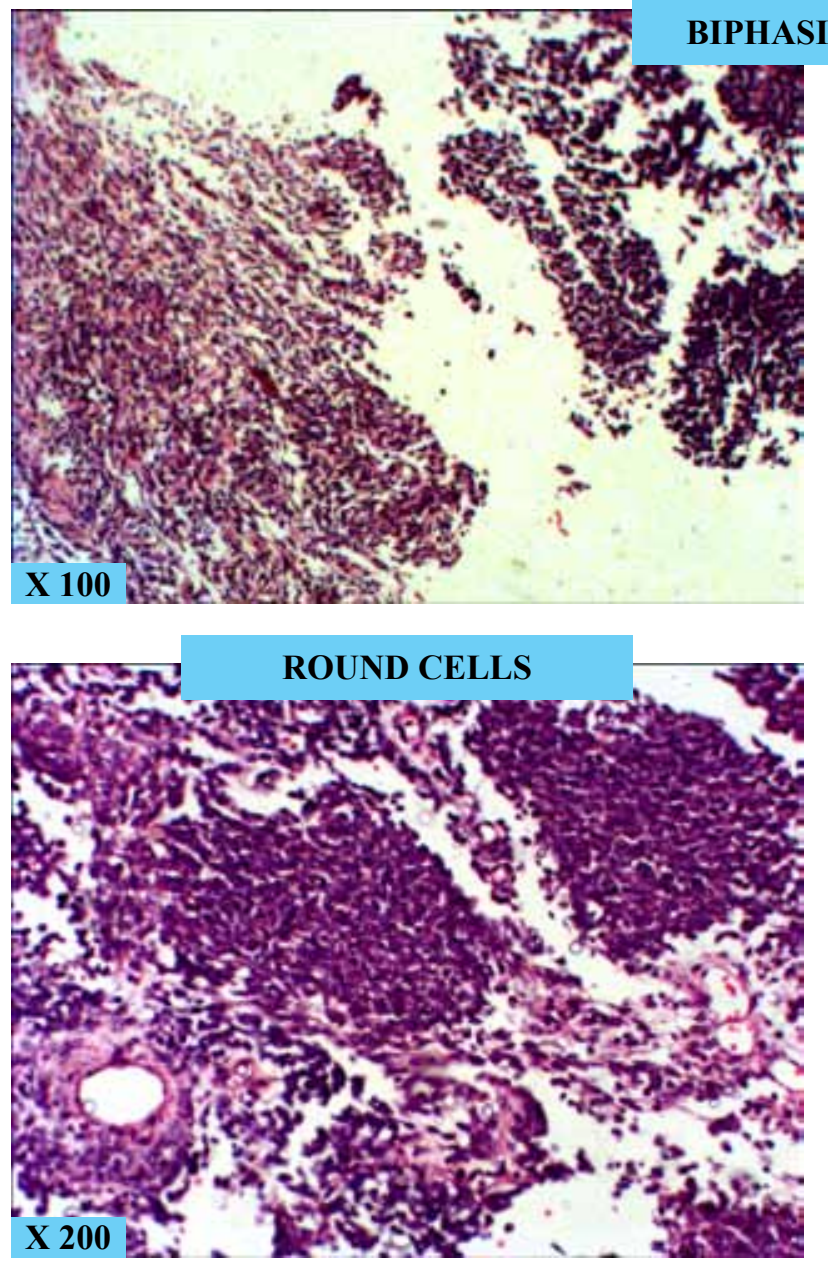
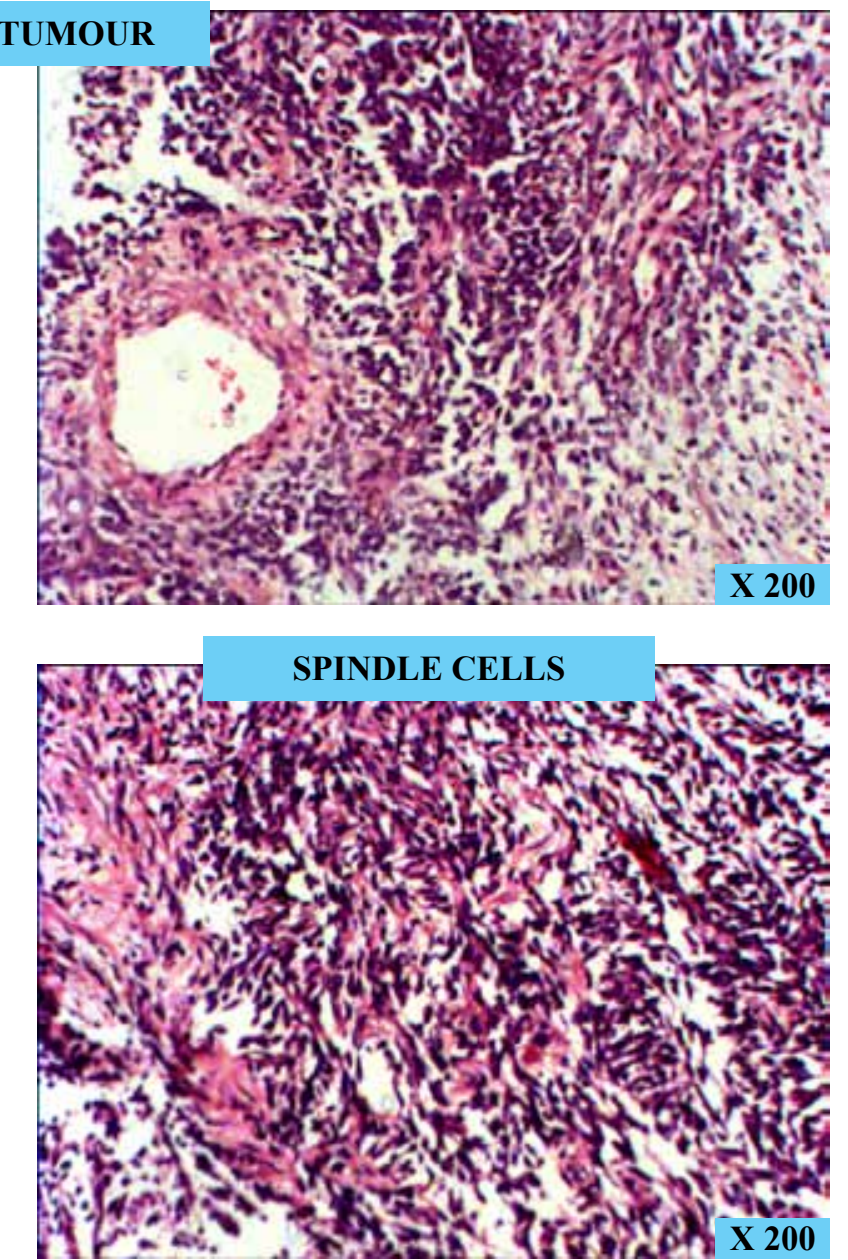

Figure 4: Histopathology of the excised specimen showing SS, biphasic variant 


\section{Discussion}

Synovial cell sarcoma (SS) is a rare mesenchymal malignancy with an incidence of approximately 2.75 cases per 100,000 people $^{1}$. It accounts for five to ten percent of all adult soft-tissue sarcomas and only five percent arises from the axial skeleton. ${ }^{2}$ It exhibits both a loco regional and a systemic pattern of spread. Despite its name, they are not associated with synovial tissue; the cell of origin has been determined to be epithelial. ${ }^{1}$ They arise from undifferentiated mesenchymal tissues that then differentiate to a tissue similar to synovium. Other unusual sites are heart, pleuropulmonary region, kidney, prostrate, liver, mediastinum, retroperitoneum, GIT, peripheral nerve. Most of the available information on SS has come from tumors localized to the extremities.

Plain radiographs may be normal in $50 \%$ of patients. In the other $50 \%$ of cases one can find masses which are difficult to visualize unless there is adjacent bony erosion. CT may show a well demarcated, hypodense mass with homogenously or heterogeneous enhancement, easily confused with other benign or malignant tumors, with calcification seen in $30 \%$ of cases. MRI is a superior modality for detecting SS, it is isointense as compared to gray matter on T1-weighted images. ${ }^{3}$ One third of lesions demonstrate a 'triple signal-intensity' pattern on T2-weighted images, that is combination of hyperintense fluid, an intermediate signal intensity similar to fat, and a slightly hypointense signal similar to fibrous tissue.

Most of the reported spinal SS had dumbbell-shaped trans-foraminal extension with a larger extraspinal and smaller intraspinal component. Symptomatology is caused mostly by the intraspinal component compressing the neural elements. Differential diagnosis includes mostly primarily nerve sheath tumors and other spinal tumors.

While managing such cases, if any spinal tumor shows features unusual for a benign nerve sheath tumor; a needle-guided biopsy upfront should be performed to obtain a diagnosis. This should be followed by a wide surgical excision with negative margins along with adjuvant radiotherapy and doxorubicin and ifosfamide based chemotherapy. ${ }^{4}$ Aim of surgery is to remove the tumor en bloc with negative margins. Traditionally, a five $\mathrm{cm}$ margin defines a negative margin in sarcoma surgery; however, in the spine this would include critical structures such as the spinal cord. Hence gross total resection with 'marginal margins' which ensures no pathologic specimen is left behind while leaving critical structures unharmed is being followed. In an unsuspected case, after the final diagnosis of SS is confirmed, a second more radical procedure can be performed. ${ }^{5}$
Use of adjuvant radiation therapy decreases the local recurrence rate. ${ }^{6}$ Radiation is proved to be superior to chemotherapy alone as adjuvant therapy.

Two chemotherapy agents, doxorubicin and ifosfamide have been used in the treatment of soft tissue sarcomas. Specifically, high dose ifosfamide has been associated with improved disease-specific survival in adult patients with high-risk primary SS and should be considered a standard part of the chemotherapy regimen. ${ }^{8}$

Histologically, synovial sarcoma is classified into three groups: biphasic type, monophasic type, and poorly differentiated type. The tumor consists of round epithelial cells, fibrous spindle cells, or both. Because of its various histologic findings, SS is often confused with other mesenchymal tumors. Immunohistochemical and cytogenetic studies are needed to distinguish synovial sarcoma from other malignant soft tissue tumors. ${ }^{9}$

Prognosis of this rare tumour is as follows the five- and ten-year survival rates for patients with synovial sarcoma are 75 and $50 \%$, respectively. ${ }^{10} \mathrm{Up}$ to $30 \%$ can have local recurrence, whereas distant metastasis is noted in $50 \%$ of the patients. Patient can have subcutaneous tissue metastasis although very rare. ${ }^{11}$ Patients with metastatic disease have a poor prognosis, with a survival of less than two years. ${ }^{12}$ The good prognostic factors include younger age, tumor size less than five $\mathrm{cm}$, negative surgical margin after complete resection, and the administration of adjuvant radiotherapy. ${ }^{13}$

\section{Conclusion}

SS of the spine is a rare entity and is more of a histopathological diagnosis than a clinical diagnosis. It can easily mimic a benign tumor due to its similarity in presentation. A high index of pre-operative suspicion, followed by a needle biopsy can help in performing a more definitive surgery upfront. If diagnosed after a limited resection, a second radical resection is suggested. In both scenarios, the patient would require adjuvant radiotherapy and chemotherapy.

\section{Conflict of Interest: None Source(s) of support: None}

\section{References}

1. Sakellaridis N, Mahera H, Pomonis S. Hemangiopericytoma-like synovial sarcoma of the lumbar spine: case report. J Neurosurg Spine. 2006;4(2):179-82. http://doi.org/10.3171/ spi.2006.4.2.179 


\section{Synovial Sarcoma of the Spine}

2. Ferrari A, De Salvo GL, Oberlin O, Casanova M, De Paoli A, Rey A, Minard V, Orbach D, Carli M, Brennan B, et al. Synovial sarcoma in children and adolescents: a critical reappraisal of staging investigations in relation to the rate of metastatic involvement at diagnosis. Eur J Cancer. 2012;48:1370-5. http://doi. org/10.1016/j.ejca.2012.01.013

3. Hirsch RJ, Yousem DM, Loevner LA, Montone KT, Chalian AA, Hayden RE, et al. Synovial sarcomas of the head and neck: MR findings. AJR Am J Roentgenol. 1997;169:1185-8. http://doi.org/10.2214/ ajr.169.4.9308488

4. Randall RL, Schabel KL, Hitchcock Y, Joyner DE, Albritton KH. Diagnosis and management of synovial sarcoma. Curr Treat Options Oncol. 2005;6:449-59. http://doi.org/10.1007/s11864-005-0024-z

5. Puffer RC, Daniels DJ, Giannini C, Pichelmann MA, Rose PS, Clarke MJ. Synovial sarcoma of the spine: A report of three cases and review of the literature. Surg Neurol Int. 2011;2:18. http://doi.org/10.4103/21527806.76939

6. Alektiar KM, Leung D, Zelefsky MJ, Brennan MF. Adjuvant radiation for stage II-B soft tissue sarcoma of the extremity. J Clin Oncol. 2002;20:1643-50. http://doi.org/10.1200/JCO.2002.20.6.1643

7. Harb WJ, Luna MA, Patel SR, Ballo MT, Roberts DB, Sturgis EM. Survival in patients with synovial sarcoma of the head and neck: Association with tumor location, size, and extension. Head Neck. 2007;29:731-40. http://doi.org/10.1002/hed.20564

8. Rosen G, Forscher C, Lowenbraun S, Eilber F, Eckardt J, Holmes C, et al. Synovial sarcoma. Uniform response of metastases to high dose ifosfamide. Cancer. 1994;73:2506-11. http:/doi. org/10.1002/1097-0142(19940515)73:10<2506::aidcncr2820731009>3.0.co;2-s

9. M. Patentalakis, M. Mermigkis, A. Kopanakis et al. Primary monophasic synovial sarcoma presenting as a pulmonary mass: a case report. Journal of Medical Case Reports, 2008; 2(1):18 http:/doi. org/10.1186/1752-1947-2-18

10. Spurrell EL, Fisher C, Thomas JM, Judson IR. Prognostic factors in advanced synovial sarcoma: an analysis of 104 patients treated at the Royal Marsden Hospital. Ann Oncol 2005;16:437-44. http://doi. org/10.1093/annonc/mdi082

11. Yang et al. Surgical management and outcome of synovial sarcoma in the spine. World Journal of Surgical Oncology. 2018;16:175, http:/doi. org/10.1186/s12957-018-1471-x

12. Eilber FC, Dry SM. Diagnosis and management of synovial sarcoma. J Surg Oncol. 2008;97(4):314-20., http://doi.org/10.1002/jso.20974

13. Spillane AJ, A'Hern R, Judson IR, Fisher C, Thomas JM Synovial sarcoma: a clinicopathologic, staging, and prognostic assessment. J Clin Oncol. 2000;18:3794803. http://doi.org/10.1200/JCO.2000.18.22.3794. 